\title{
EL DIACONADO, HOY
}

\section{Los mayores obstáculos a su perceptibilidad}

DOI: https://doi.org/10.52039/seminarios.v51i176.719
Autor: Alphonse Borras. Profesor de Derecho canónico en la universidad de Louvain-le-Neuve, es vicario general de la diócesis de Lieja.
Traducido del texto original francés por Alonso Morata, Esprit et Vie, 111 (04) pp. 3-11.

¿Cómo puede leerse el diaconado como un ministerio diferente y con entidad propia en la misión de la Iglesia? ¿Qué funciones tiene? ¿Cuáles son los obstáculos para su legibilidad? El P. Borras intenta responder a estos y otros interrogantes en el presente estudio.

¿Es hoy perceptible el diaconado? La liturgia y de manera especial la Eucaristía son lugares privilegiados de perceptibilidad de la Iglesia y de sus ministerios- la Eucaristía es a su vez la principal manifestación del misterio de la Iglesia que se realiza en este lugar (Sacrosantum concilium, $n^{\circ} 41 b$; ver Lumen gentium, $n^{\circ} 26 a$ ). Durante muchos siglos, en la Iglesia latina, los diáconos sólo existían en la liturgia hasta el punto de que su perceptibilidad litúrgica ha sido un verdadero espejismo sobre el ministerio efectivo en los otros aspectos de la vida eclesial. La liturgia no es el único lugar de perceptibilidad de los diáconos. Tras la restauración del diaconado permanente, se puede encontrar a los diáconos en otros lugares además de la liturgia incluso aunque, en estos otros lugares, su visibilidad sea bastante más discreta en el sentido de que no pretende imponerse como tal y que, paradógicamente, resaltarlo más perjudicaría el ejercicio del ministerio laical. 
Los diáconos son reconocibles en los diferentes lugares en los que dan visibilidad a su ministerio. Se pueden sacar principalmente tres tipos de inserción'1.

En primer lugar hay diáconos que privilegian una presencia en su medio profesional, sociocultural o asociativo. Esta presencia no es en manera alguna de «puro ocultamiento»; se deja interpelar con mucha frecuencia por los mismos intereses y, en todo caso, por su entorno. No falta ver en ello ministros de la Iglesia que, en virtud de la ordenación, representan de manera singular la solicitud de Cristo en el medio que les ocupa. Parece que en Francia uno de cada cuatro diáconos ejerce un ministerio principalmente unido a su vida profesional.

Hay otro grupo de diáconos que se hacen presentes en un servicio de tipo caritativo o humanitario, desde el ámbito social al médico pasando por la educación, en instituciones pluralistas o confesionales y sin que su presencia esté necesariamente determinada por una mirada apostólica. Alrededor de 2 de cada cinco diáconos franceses ejercen como ministerio prioritario -que no exclusivo- un servicio de tipo caritativo. Como el primer tipo de unión de inserción, esta presencia de los diáconos se ve igualmente «en plena vida» por tomar esta expresión del episcopado francés de 1970. Se vive de modo parecido al ministerio de los sacerdotes-obreros. Pero, a diferencia de ellos, los diáconos permanentes están desde el principio en ese medio o institución.

Hay, por fin, otro grupo de diáconos que están presentes en las comunidades cristianas, y en particular en las parroquias, para desempeñar allí cargos eclesiales. Sin ser únicamente litúrgicos, estos cargos están ligados al anuncio de la fe y a la acción catequética-desde el despertar de la fe a la formación permanente pasando por la iniciación en el misterio pascual y el aprendizaje de la vida cristiana- también incluso en la dirección de

${ }^{1}$ Recojo aquí una tipología en tres partes presentada por J. Rigal, L'Église en quête d'avenir. Reflexions et propositions pour des temps nouveaux, París, Éd. Du Cerf, coll. «Théologies», 2003, p. 164-165. Más adelante en esta misma obra, el autor se basa en los documentos del Comité nacional francés del diaconado de 2002 relativos a enero de 2000 para repartir los diferentes compromisos de los diáconos. Se da el hecho de que el 39\% de los diáconos franceses ejercía como ministerio prioritario (y no exclusivo) un servicio de tipo caritativo; $27 \%$ un ministerio unido en principio a la vida profesional; $23 \%$ un ministerio especialmente litúrgico. En el mismo J. Rigal, la proporción sería notablemente diferente en otros países tales como Alemania o Brasil, en los que las responsabilidades litúrgicas y parroquiales son predominantes. 
las comunidades. Bajo este último punto de vista, los diáconos ejercen funciones eclesiales aprovechando la disminución del número de los sacerdotes y su visibilidad se efectúa en definitiva principalmente en el plano litúrgico. La cuarta parte de los diáconos franceses tiene una inserción prioritaria eclesial, sin duda bajo el efecto de un retiro o (pre-) profesional y bajo presión de «necesidades de comunidades habituadas a una gama importante de servicios ${ }^{2} \gg$.

No basta con que los diáconos sean reconocibles -visibles- en la comunidad eclesial y en la vida social. Es necesario también que su presencia sea legible, inteligible. Más allá de su visibilidad, importa hoy, cuarenta años después de la restauración del ejercicio permanente del Diaconado, preguntarse sobre su «legibilidad». Este término designa la capacidad de la realidad estudiada de traducir, al mismo tiempo, su razón de ser (en alemán warum) y su finalidad (en alemán wozu): la razón de ser y finalidad del diaconado ¿son comprensibles para todos?

Se podía pensar de primera impresión que el diaconado tiene una «legibilidad» que se deja descifrar de manera inequívoca. En este sentido el ministerio diaconal debería -o podría- de entrada dejar clara su razón de ser así como su meta- ese «para qué» así como el «porqué» de su existencia en el paisaje actual de la Iglesia. ¿No existe cierta inclinación ingenua a creer en esta lectura unívoca como si el simple hecho de constatar la existencia de algo fuera suficiente para descubrir su sentido? Se impone un discernimiento eclesial -es decir como Iglesia- «a la luz del sentido de la fe»: se trata en este caso de «distinguir por la fe la acción del Espíritu de Dios»3. Importa desde ese momento, escrutar lo que dice el Espíritu y lo que nos inspira su acción en orden al restablecimiento del diaconado como ministerio efectivo.

La legibilidad de una institución como el diaconado no es un fin en sí misma; remite ésta a otros ministerios ordenados, cara a la unidad del ministerio. Remite a la Iglesia local, en la que se realiza de verdad la Iglesia de Dios, más que la Iglesia en su totalidad entendida como la comunión de las Iglesias. Remite, en definitiva, al misterio de la alianza que

${ }^{2}$ Esta expresión es de la Comisión Teológica Internacional, «El Diaconado, evolución y perspectivas», La Documentation catholique, $\mathrm{n}^{\circ} 100$ (03) 58-107, en este caso p. 91. ulteriormente se citará CTI, «El Diaconado».

${ }^{3}$ CTI, El Diaconado, p. 58. La consideración de los hechos, recuerda este documento, no se convierte en «lugar teológico» si no se hace a la luz del sentido de la fe. 
informa la comunidad eclesial y que es a la vez acogida, traducida y servida con la participación de todos, cada uno según sus carismas, para el anuncio de la Buena nueva en este lugar concreto. Es pues en el marco global de la Iglesia y de su misión, donde es necesario comprender e interpretar el diaconado. Esta perspectiva sistemática no soslaya una realidad; la inscribe en una unidad que forma sistema y cuyos elementos están en interacción. Todo se relaciona: la Iglesia, su misión en la historia, sus ministros y el misterio que sirve y le informa.

Cuarenta años después de la decisión de los Padres del Vaticano II de restablecer el diaconado permanente, se ven sin duda mejor que entonces los obstáculos para su legibilidad que debe ir más allá de las Iglesias locales que han optado por la reactivación de este ministerio. La visión más clara de estos obstáculos podría servir de puerta para la elaboración de una reflexión teológica sobre el diaconado. Esto es lo que propongo hacer en estas páginas, refiriéndome, si llega el caso, al reciente documento teológico -no magisterial- de la Comisión teológica internacional. Hecho este camino, se podrá apreciar aquello que parece ya adquirido en la doctrina común o lo que, por el contrario, debe ser aún objeto de profundización teológica.

\section{El peso secular del monopolio ministerial de los sacerdotes}

Un primer obstáculo es, sin duda alguna, el peso secular del monopolio ministerial de los sacerdotes. Éste ha aparecido de manera progresiva bajo el efecto de diferentes factores. Pienso, principalmente en el establecimiento de un régimen de cristiandad con la referencia e incluso la participación de todos los ciudadanos en una sola y única religión, la cristiana, representando de este modo el papel de religión civil y proporcionando a la sociedad, tanto como al Estado, propuestas para la satisfacción de las necesidades religiosas.

En este contexto de cristiandad, el monopolio ministerial de los presbíteros se explica por la clericalización de los ministerios. Ésta ha resultado del ajuste sucesivo y lineal hacia el sacerdocio, de la elaboración de una carrera eclesiástica que determina un estado clerical, así como la separación progresiva del clero por el estilo de vida inspirado en los monjes y en los canónigos y sobre todo por el estado de vida -abstinencia 
sexual en los casados en el principio, después impedimento canónico para los clérigos casados de acceder a las órdenes mayores y, por último, generalización del celibato eclesiástico-.

El monopolio ministerial de los presbíteros se traduce en los hechos y en la mentalidad. El ministerio presbiteral ha acabado por absorber en él el cumplimiento de la mayor parte de las tareas indispensables para la construcción de la comunidad y la realización de su misión ${ }^{4}$. Esto se verifica de manera particular en el ámbito parroquial en donde, hasta la llegada del Vaticano II, la comunidad «vivía en el presbítero y vivía del presbítero», como recuerda B. Sesboüé: la parroquia «reposaba totalmente sobre él. Su figura de permanencia eclesial llevaba a todas las responsabilidades a concentrarse en él: pastoral, catecismo, finanzas, obras, transformación de la iglesia, coral, incluso la Acción católica. [...] Confiscaba en su persona todos los órdenes, siendo a la vez, ostiario, lector, acólito y exorcista, subdiácono, diácono y preste. traducía una realidad evidente, porque él abría la Iglesia, hacía todas las lecturas, hacía sonar las campanas. En pocas palabras, caía sobre él todo el peso de la iniciativa y de la animación ${ }^{5} \gg$.

Durante muchos siglos, esta solución ha sido aceptada generalmente por la comunidad. Ésta la encontraba cómoda: se descargaba en el sacerdote de sus responsabilidades sin tener necesariamente conciencia de hacerlo ya que se representaba la vida eclesial a partir de la separación «clero-laicado». Lo cierto es que a la vuelta del segundo milenio, los bautizados se habían hecho poco a poco a la relegación de los laicos al rango de administrados, simples sujetos pasivos en la Iglesia -para lo espiritual, decían, activos para lo temporal-y, correlativamente, se habían habituado a la exaltación del clero en sentido amplio, comprendidos también los monjes, los únicos sujetos activos en la Iglesia. La separación entre administradores y administrados ha hundido la focalización en la etapa última del cursus clerical, el sacerdote de los sacerdotes -el episcopado era visto

\footnotetext{
4 «La historia del ministerio, escribe CTI, muestra que las unciones sacerdotales han tenido la tendencia de absorber las funciones inferiores. Cuando la carrera clerical queda establecida, cada grado posee competencias suplementarias en relación al grado inferior: lo que hace un diácono, lo puede hacer también un presbítero. En el punto más alto de la jerarquía, el obispo puede ejercer la totalidad de las funciones eclesiásticas» CTI, "Le Diaconat", p. 74.

${ }^{5}$ B. Seboüe, Pour une theologie oecumenique, Paris, Ed. du Cerf, coll. "Cogitatio fidei" n 160, 1990, p. 283.
} 
sobre todo como una jurisdicción o una dignidad-. Esta focalización entrañaba, de hecho, una reducción del ministerio al de los sacerdotes, percibidos, si no comprendidos, como los únicos ministros de la Iglesia ${ }^{6}$.

Más aún, la consecuencia de este estado de cosas ha sido que «la imagen de la Iglesia era prácticamente confundida con la del sacerdote», éste había llegado a ser el modelo del cristiano a secas 7 . Esto se comprende tanto más en este mundo multisecular de cristiandad donde, después del viraje constantiniano, la distinción «clero-laicos» se había transportado sutilmente a la distinción entre comunidad eclesial y la sociedad entorno. En una cristiandad que se había alimentado de una representación totalizante de la realidad -la mayor parte de los ciudadanos, si no todos, eran cristianos- la dimensión intrínsecamente misionera de la Iglesia no se había vivido más que en relación al exterior del mundo cristiano, a los límites de éste, en referencia a los infieles, a saber los musulmanes hasta el siglo XVI, después los indios y otros individuos hasta las últimas colonizaciones del siglo XX.

Es importante darse cuenta de que el monopolio ministerial de los sacerdotes se da en detrimento de todos los ministerios, el diaconado incluido. Personalmente considero que la pluriministerialidad es una condición necesaria, pero no suficiente, para una buena recepción del diaconado. Entretanto, es necesario medir bien de qué modo este monopolio continúa marcando las representaciones comunes aun cuando, en los hechos, después de cuarenta años asistimos a una diversificación de los ministerios y a la emergencia del diaconado.

El peso de las representaciones cuenta mucho, según pienso, en la legibilidad del diaconado permanente, sobre todo en un contexto de falta de sacerdotes en Occidente en donde los diáconos son percibidos, cuando no esperados, como sustitutos de los sacerdotes. De donde la presión muy fuerte sobre la clase de tareas confiadas a los diáconos y la percepción del diaconado como un ministerio de suplencia presbiteral: «Cumpliendo así las tareas tradicionalmente confiadas a los sacerdotes, los diáconos corren

${ }^{6}$ A lo largo de los siglos, los sacerdotes han suplido no solamente a los diáconos, han asumido también diversos carismas susceptibles de ser ejercitados por otros bautizados. Ver P. Winninger, "Les ministères des diacres dans l'Église d'aujourd'hui", en G. Barauna, L'Église de VaticanII, Paris, Éd. du Cerf, coll. "Unam sanctam" n 51c, t 3, 1966, p. 1000.

${ }^{7}$ B. Sesboüé, Pour une theologie oecuménique, p. 283. 
el riesgo de aparecer como "sacerdotes incompletos"» o «laicos avanzados ${ }^{8} \gg$. En este contexto, el diaconado tiende a tomar como punto de referencia el presbiterado. Esta evolución queda problemática: hace más difícil la emergencia de una identidad propia de un ministerio diaconal ${ }^{9}$. Esto no favorece su legibilidad.

\section{La ausencia milenaria del ministerio del diaconado}

El segundo obstáculo para la legibilidad del diaconado es consecuencia del anterior: el ministerio diaconal no se ha ejercido desde hace muchos siglos, a no ser en la liturgia. A fuerza de haber sido «desactivado» en la vida eclesial -según la metáfora de la informática- el ministerio diaconal no favorece representaciones propias si no es por ciertas evocaciones anteriores al siglos IV y V asociándole estrechamente al ministerio del obispo. Por eso se oye decir que los diáconos están al servicio de los obispos. Estas evocaciones pecan de anacronismo tomando a la Iglesia antigua no como referencia, sino como modelo para hoy. Durante los primeros siglos los diáconos aparecen como los primeros, si no los únicos, colaboradores del obispo en la edificación de la Iglesia local y la realización de su misión.

En esa época, el ministerio episcopal garantizaba él solo la presidencia de las comunidades, los sacerdotes, los presbíteros o más bien el presbyterium le ayudaba en el gobierno y, por esta razón, concelebran con él la eucaristía. Los diáconos estaban a disposición del obispo para llevar a término sus órdenes, pero quedaban excluidos de la participación en el Consejo de los presbíteros. Su ministerio era, sin duda alguna, litúrgico, de manera especial en la sinapsis eucarística mediante la animación de la oración de la asamblea, la asistencia litúrgica del obispo, la presentación de las ofrendas en la eucaristía, la distribución de la sagrada comunión. Intervenían también en la iniciación cristiana, en particular el momento del bautismo cuyo papel era el de acompañar al obispo o al presbítero y servir los «óleos de catecúmenos y el crisma y también bajar hasta el agua

8 CTI, "Le Diaconat", p. 90.

9 Ver Sesboüé “Quelle est l'identité ministerielle du diacre?", en J. Doré (Dir), L’Église á venir. Mélanges offerts à J. Hoffmann, Paris, Ed. du Cerf, 1999, p.255-257; A. Borras "Repéres pour une théologie du diaconat" Prêtres diocésains, n 1371 (1999), p. 622-644. 
con el que había de recibir el bautismo ${ }^{10} \gg$. Los diáconos tenían una actividad de enseñanza de tipo catequístico especialmente y un ministerio de proximidad y de consuelo con personas enfrentadas a pruebas como la enfermedad, el sufrimiento, la marginación. Es sobre todo en ese aspecto del ejercicio de la caridad donde desempeñaban una actividad social a favor de los pobres de toda clase, en unión estrecha con el obispo por lo demás naturalmente calificado de «padre de los pobres». Esto aclara su implicación en la administración de los bienes de la Iglesia local.

Esta rápida evocación del diaconado de los primeros siglos nos permite establecer algunas diferencias en el ministerio concreto de los diáconos de hoy en una Iglesia que, tras la era constantiniana, no está presidida solamente por los obispos sino también por los presbíteros. Tras la restauración del diaconado permanente, se ve a diáconos vinculados al servicio de los curas de parroquia (y no solo en el plano de Iglesia local o diócesis), que hacen la homilía (acto antiguamente reservado al obispo o al presbítero), e incluso celebran el bautismo (nunca visto en la iglesia antigua, si no era en caso de necesidad, incluso hoy no se da en la iglesia oriental). Los diáconos están raramente implicados en la administración de los bienes y en la gestión financiera de las diócesis mientras que están muchas veces asociados a asociaciones o servicios de caridad no confesionales (hecho antes difícilmente concebible fuera del marco de la comunidad eclesial y directamente en su beneficio). Se busca fácilmente que la visibilidad actual de las tareas diaconales no se apoye en representaciones de antes. Estas sirven todo lo más como referencia inspiradora. De aquí la dificultad de representarse el ministerio diaconal tras el silencio de tantos siglos.

Además, la desactivación multisecular del diaconado permanente se efectúa en el contexto de una teología del ministerio, hasta hace poco, fuertemente enfocado al sacerdocio de los prestes porque estaba centrado en la celebración de los sacramentos, en especial de la eucaristía. Es verdad que la función litúrgica de los diáconos es la única que tenemos durante muchos siglos hasta el punto de que, antes del Vaticano II, era también ejercida en buena y propia forma por ministros que se ponían la dalmática pero, con mucha frecuencia, se trataba de prestes que hacían el oficio de diáconos (y subdiáconos). Este vestigio litúrgico del ejercicio

\footnotetext{
10 Según los términos de la Tradición apostólica de Hipólito de Roma (París, Ed. du Cerf, col. «Sources chrétiennes», $\mathrm{n}^{\circ} 11$ bis), en el capítulo 21 que cita la CTI («Le diaconat», p. 65).
} 
del diaconado nos recuerda que históricamente la reducción del diaconado a su función litúrgica era el signo, el efecto tanto más que la causa, de su declive en Occidente11.

El reestablecimiento reciente del ejercicio del diaconado hace ver una diversidad de concretización de este ministerio. La más visible se da en la liturgia, aún es necesario que el diácono no se aísle en intervenciones mínimas y esporádicas o que no se deje reducir a actuar de acólito. En estas circunstancias, los fieles no se engañan: el diácono les aparece como un acólito de lujo. En realidad. Los diáconos cumplen otras tareas litúrgicas como la homilía y cumplen funciones sacramentales ${ }^{12}$. En cuanto a las tareas en el campo de la caridad, han sido asumidas tras largo tiempo por otros bautizados, individual o colectivamente, especialmente por los monjes en primer lugar y más extensamente por los religiosos, y hoy por algunos servicios de Iglesia -sin olvidar, desde el fin del Antiguo Régimen, el papel de servicios públicos o de asociaciones no confesionales. Si estas tareas están actualmente desempeñadas por diáconos, éstas no se perciben espontáneamente como que estén más particularmente unidas al ministerio de los diáconos, al menos no más que lo están al ministerio de los sacerdotes, ni siquiera de animadores laicos en pastoral.

\section{La dificultad de entrar en una comprensión sacramental}

A esto se añade la cultura contemporánea cuyos parámetros oscurecen la capacidad simbólica y la comprensión sacramental del ministerio ordenado, principalmente de los diáconos. Por capacidad simbólica

11 En Oriente, los diáconos no han dejado de ser un orden permanente del clero, pero para los servicios litúrgicos (v.CTI, «Le diaconat», p.73) Su ministerio es perpetuado en la liturgia aun cuando se tradujera en parte con otras tareas eclesiales en la vida de las comunidades y su reinado misionero. En Occidente también, la actividad de los diáconos está prácticamente limitado a tareas litúrgicas (Ib. P.74). En la Iglesia latina, las funciones diaconales han sido recuperadas en las «misas de tres» en las que uno de ellos «hacía» el papel de diácono.

12 Ver CTI, «Le diaconat», p. 90. Me quedo perplejo con respecto al bautismo administrado por los diáconos incluso si son reconocidos «ministros ordinarios» de este sacramento (Ver CIC 1983, c. 861, § 1), Si el bautismo es el sacramento por el cual los seres humanos son incorporados a la Iglesia -Cuerpo eclesial de Cristo-, no debería ser celebrado por aquel que preside a la comunidad eclesial y su eucaristía por la que los bautizados se convierten en lo que han recibido, a saber el Cuerpo de Cristo? 
entiendo la relación que se establece entre el ministerio ordenado -y sin duda con más amplitud la unidad de los ministerios- y la unidad de la comunidad eclesial. Se trata de esa relación entre «algunos-unos»y «todos» en el seno del cuerpo eclesial que permite a la Iglesia a «permanecer unida» (gr. sunballein). Es Dios por Cristo y el Espíritu de quien tiene (y viene) la comunidad eclesial. Los ministros ordenados significan que nada hay en la Iglesia si no es por iniciativa gratuita de Dios. La unión de los fieles, ministros incluidos, significa que no hay Iglesia si no por la adhesión libre y gozosa a la fe.

Esta capacidad simbólica sin duda que no es espontáneamente buscada por los católicos que chapotean en una cultura marcada por la exaltación del individuo - patrón y medida de todo, incluso si se arrepiente de sus ilusiones totalizantes, además totalitarias- y una comprensión del vínculo social como compromiso negociable y sin cesar negociada entre todos. Las reflexiones actuales en sociología de la religión muestran en primer lugar que toda institución, secular o eclesial, y en particular la autoridad pastoral deben hoy contar con la implicación de todos los que los renegocian según sus aspiraciones y deseos ${ }^{13}$. En este contexto, la función simbolizante de «unos pocos» tiene difícil evidenciarse a los ojos de «todos» para quienes, sobre la base de una verdad eclesiológica, ciertamente, pero también según una lectura democrática típicamente moderna. «la Iglesia es tarea de todos». Esta afirmación es fundamentalmente verdadera, pero unilateralmente considerada, olvida que la Iglesia, es en su comienzo la Iglesia de Dios, la convocación de parte de Dios dirigida a la humanidad para vivir en gracia -«verdad» que la función simbólica de «unos pocos»- recuerda, significa y hace efectiva en la vida eclesial y el testimonio evangélico.

Pero es también la comprensión sacramental del ministro ordenado la que es difícilmente captable para nuestros contemporáneos postmodernos, católicos incluidos. Este obstáculo debe ser tenido en cuenta en el momento en el que la sacramentalidad del diaconado se convierte, a los ojos de muchos, como los miembros de la Comisión teológica internacional, en el criterio central, incluso único, para el tratamiento de todas las

13 Ver por ejemplo L. VOYÉ, L'institution eclesiale face aux développements, en V. SARAGLOU et HUTSEBAULT (dir.), Religión et développemen humain; París. Éd- L'Harmattan, col. «Religión et sciences humaines», 2001, 275-293; D.HERVIEU-LÉGER, Paris, Bayard Éd., 2003, en particular p. 266-311. 
demás cuestiones referidas a la teología del diaconado ${ }^{14}$. Además «insistir en la sacramentalidad del diaconado es insistir en primer lugar y antes que nada en la unidad interior del sacramento del orden ${ }^{15}$.» Es tanto la sacramentalidad del ministerio ordenado en general como el misterio al que sirve los que son poco o mal percibidos por una mentalidad contemporánea marcada por criterios de objetividad científica, de eficacia tecnológica y de representación democrática.

Según estos parámetros de la cultura contemporánea, el saber prima sobre la relación simbólica, la competencia técnica es distinta del valor moral y la autoridad proviene de una delegación formal de la base: el ministro ordenado es comprendido como un conjunto de tareas a hacer en beneficio de la comunidad eclesial o de la colectividad humana. De donde, a los ojos de muchos, la dificultad de captar la diferencia entre lo que «hace» un diácono y las mismas funciones ejercidas por un laico. Se vuelve con esto a ese tema clásico de las potestades al que la mentalidad moderna sensible a la eficiencia, a la eficacia y a la forma concede una nueva importancia: ¿qué puede «hacer» el diácono que no pueda «hacer» el laico ${ }^{16}$ ?

14 Ver CTI, «Le diaconat», p.94: «Es a partir de su sacramentalidad que será preciso tratar otras cuestiones concernientes a la teología del diaconado». Esta afirmación de la sacramentalidad podría llegar a ser definitiva ya por «una intervención del Magisterio más directa y explícita» ya «por una articulación eclesiológica más acertada de los diferentes elementos» (p.83) Remito de buena gana a las reflexiones de D. GONNEAUD, «Une lecture du document de la Commission théologique internationale. Le diaconat, evolution et perspectives», NRT $n^{\circ}$ 125 (2003), 401-417, en especial 407-409 y 410-412. Nuestro colega valora mucho esta temática de la sacramentalidad del diaconado como hilo conductor del documento de la CTI. Tiene la ventaja de no «encerrarse enseguida en las inextricables dificultades unidas a la noción de sacerdocio» (414). Al mismo tiempo, sugiere que una lógica puramente doctrinal centrada en esta temática es insuficiente si no se articula en una recuperación teológica de la experiencia, una comprensión de la comunión, una aproximación del orden diaconal a partir de la teología de la Iglesia local y una consideración de la relación de ésta con el mundo (ver p. 414-416).

15 D. GONNEAUD, «Une lecture du document de la Commission theologique internationale», p. 407.

${ }^{16}$ Curiosamente el contexto cultural da como una renovación del interés de esta cuestión de las potestades inherentes al sacramento del orden. Se comprende de largo las sabias reflexiones de la CTI: «Sin duda es una aproximación muy pequeña como reducir la sacramentalidad a la cuestión de las potestades; la Eclesiología ofrece perspectivas más amplias y más ricas. Pero, en el caso del sacramento del orden, no se puede omitir esta cuestión evocando la minucia citada. Los otros dos grados del orden, el episcopado y el presbiterado, dan una capacidad, en razón de la ordenación sacramental, para tareas que una persona no ordenada no puede (válidamente) hacer. ¿Por qué habría de ser de otra manera para el diaconado? ¿Acaso la diferencia 
En este contexto cultural muchos fieles tienen difícil encontrar la referencia al «misterio» entendido como la acción del Dios trinitario en el corazón de nuestra historia. Los ministros que la Iglesia ordena son llamados y enviados para servir este misterio que no es propiedad suya, ni objeto de su iniciativa o de su empresa, y menos resultado de sus cualidades o fruto de su ingenio. Es un don de Dios que se da a conocer en nuestra historia por Jesucristo en el Espíritu y que llama a seres humanos a su comunión de vida. Este misterio, a ejemplo del obispo y del preste, el diácono lo realiza en tanto que está consagrado. Dicho de otra manera, este misterio informa al ministro que los ejerce. No hay pura exterioridad. Está afectado por ella. Para servir a la obra de Dios que se revela y la fe apostólica que lo testifica, el diácono, como los demás ministros ordenados, ha sido investido por un sacramento que le toma toda su vida y para toda la vida.

Además, esta unión intrínseca entre el misterio que se sirve y el misterio que nos habita está a la base de la configuración particular con Cristo, «diácono y servidor de todos ${ }^{17} \gg$. La teología latina ha elaborado la teoría del «carácter indeleble» para expresar esta disposición a la gracia unida al ministerio ordenado ${ }^{18}$. A partir de esta doctrina, se puede entender la diferencia esencial entre el diácono al servicio del altar y cualquier otro ministerio litúrgico. El carácter sacramental «corrobora la fidelidad de Dios a sus dones, implica la no-reiterabilidad del sacramento y la estabilidad durable en el servicio eclesial ${ }^{19} »$. En esta perspectiva, la Comisión Teológica internacional ha subrayado que lo que permanece decisivo en la

reside en el cómo del ejercicio de los munera o en la cualidad personal del que lo realiza? Pero, ¿cómo hacerlo teológicamente creíble? Si, de hecho, estas funciones pueden ser ejercidas por un laico, cómo justificar que tienen como fuente una ordenación sacramental nueva y distinta?» CTI, «Le diaconat», 83. en el plano de la doctrina canónica, el contexto cultural ya sensible al «hecho» incita a poner de nuevo, si no por la primera vez, la cuestión de la potestas sacra en el jefe de los diáconos. Me permito remitir a un estudio que aparecerá próximamente: A. BORRAS, «Ministerio diaconal y potestas sacra».

${ }^{17}$ La expresión viene del Catecismo de la Iglesia católica que habla de un «sello» inefable que configura con Cristo «diacre» (Ed. 1997, n 1570). Este remite a la doctrina del «carácter indeleble» aplicada al diaconado del que habla el motu proprio Sacrum diaconatus ordinem (15.08.1967) mientras que el Vaticano II no había hecho mención explícita alguna.

18 Ver a H. LEGRAND, «Carácter indeleble y teología del ministerio», Concilium, 74 (72) $63-70$.

19 CONGREGACIÓN PARA EL CLERO, «Directorio para el ministerio y vida de los diáconos permanentes », DC 93 (1998) 63-70. 
acción diaconal será el «ser» más que el «hacer»20, aunque en apariencia se trate de las mismas funciones que realiza un laico. «En la acción diaconal se realiza una presencia especial de Cristo Cabeza y Siervo propia de la gracia sacramental, a la configuración con él y a la dimensión comunitaria y pública de las tareas que son ejercidas en el nombre de la Iglesia ${ }^{21}{ }_{\gg}$.

\section{Las obligaciones de una laboriosa salida de la sociedad de cristiandad}

Esta breve evocación es suficiente para medir la dificultad de pensar y poner en marcha la sacramentalidad del ministerio ordenado, en especial de los diáconos. Queda aún otro obstáculo para su legibilidad: reside en las circunstancias actuales o en el momento presente de «salida» de cristiandad. Tras el siglo IV y a lo largo de los siglos se instauró progresivamente este régimen en el que todos los ciudadanos participaban de la misma religión. Políticamente, este régimen finalizó con la revolución francesa. Este consagraba en el plano político, la emergencia de una nueva cultura iniciada en el siglo XIII y centrada en el sujeto, protagonista de su existencia, incluso protagonista de la historia. Esta nueva cultura que había madurado con las Luces estaba caracterizada, entre otras cosas, por la distinción, si no por la separación de diferentes registros de la vida individual y colectiva. La religión separada del Estado dependía desde ese momento de la libertad de conciencia de los ciudadanos que veían reconocérseles la libertad de adherirse a un culto y la de ejercerlo públicamente.

Desde el principio, esta nueva cultura centrada en el sujeto lleva en germen el pluralismo ideológico y, al final, sólo podía dar lugar a una sociedad plural por la diversidad de creencias y convicciones. Pero ha faltado tiempo para que esa cultura despliegue toda su potencialidad en la vida social -la historia del siglo XX lo testifica con sus veleidades de restauración-. Ha faltado tiempo también para que supere su ilustración racionalista de omnisciencia así como su vana pretensión de dominio del progreso y de la historia

${ }^{20}$ No se puede separar el ser y el hacer: el ser se realiza por el hacer que le lleva a su cumplimiento. Hay que estar atento para no instalarse en este tipo de divergencia ideológica del que el pensamiento occidental no se acaba de curar. El repetir en materia de Iglesia y ministerios no aporta nada y acentúa la dificultad de pensar la sacramentalidad que no se sitúa simplemente del lado del «ser», sino del «hacer», desde el momento en el que los sacramentos son, según la doctrina clásica, signos que realizan aquello que significan y que significan lo que realizan.

${ }^{21}$ CTI «Le diaconat», p. 106. 
para desembarazarse por fin de ideologías proveedoras de sentido, especie de mesianismos terrestres que funcionaban como religiones secularizadas- la historia trágica del siglo XX lo muestra. En esta cultura antropocéntrica, democrática y pluralista, las religiones, el cristianismo en particular, y finalmente, la Iglesia católica resisten difícilmente a una crisis de transmisión, a una negociación interna para sus miembros, a una demanda de obligación institucional, a una recomposición ecléctica según las necesidades religiosas, a la influencia de la emoción y elecciones similares, etc.

Asistimos al fin de la sociedad de cristiandad, entendida como régimen cultural, social y político que descansaba en la adhesión o al menos la referencia de todos a la fe cristiana. Los pensadores y teólogos católicos ya nos habían prevenido, tras decenas, del fin de la sociedad de cristiandad $^{22}$. Más recientemente, corresponde al episcopado de Occidente advertir a los fieles y motivarles para una nueva evangelización ${ }^{23}$. Uno de los efectos más importantes como indicador de este fin del estado de cristiandad es la escasez de sacerdotes que traduce a la vez una disminución numérica de cristianos y una representatividad menor de los diferentes estratos y categorías sociales en la parroquia, principal lugar de visibilidad de la Iglesia. Hay menos sacerdotes porque hay menos católicos. Esto no sucede sin influir en el ministerio de los sacerdotes ${ }^{24}$. Y no deja de tener efecto en la percepción del diaconado y, en definitiva, en la visibilidad de los diáconos.

22 Es suficiente con mencionar E. Mounier, Feu la chrétienté, Paris, Ed. Du Cerf, el K. Rahner, Misión y gracia, Paris Ed. Mame, 1962, p. 31-50 o más recientemente A:HEDON «Tenir debut quand tout bascule», Christus 186, (00) 205-212 o también K.KOCH, «La présence de l’Église dans les societés secularisées d'Europe», en Philippe Baud (direc), Le christianisme a-t-il un avenir? Saint Maurice, Ed Saint Augustin, 2000, p. 151-188, en especial 165-168.

23 Ver Obispos de Francia, Proponer la fe en la sociedad actual, III, Carta a los católicos de Francia. París, Ed. Du Cerf, col. "Documents des Églises", 1996, 20. Otros episcopados se expresan en términos similares a partir de tomarse en serio nuestra situación cultural. Entre otros: Asamblea de los obispos de Québec. Anunciar el evangelio en la cultura actual en Québec, Québec, ed FIDES, col. "L'Église aux quatre vents", 1999. podría extenderme a los obispos de Alemania: Die Deutschen Bischöfe, "Zein zur Aussaat" Missionaris Kirche sein; Bonn, 2000. Recuerdo en cualquier caso la reciente declaración de los obispos de Bélgica, Enviados para anunciar, Bruselas, Licap, 2003, y el mismo propósito del obispo de Roma en su encíclica para la apertura del tercer milenio: "Se debe considerar, como desde ahora pasado, incluso en los países de antigua evangelización, la situación de una sociedad de cristiandad" (Juan Pablo II, NMI, de 6 de enero de 2001, ${ }^{\circ} 40$. La documentation catholique, 98 (01).

24 Me permito citar mi estudio: A. BORRAS: ¿Qué futuro para los sacerdotes? ¿qué sacerdotes para el futuro? Esprit et Vie, 51 (02) 3-18, especialmente 6-8. SEMINARIOS 166 (02) 301-332. 
En el territorio de Occidente, se constata que muchos católicos comienzan a comprender que «ya nada será como antes». Y, por lo tanto, muchos ciudadanos mantienen una demanda religiosa de la Iglesia principalmente en términos de ritos de paso. Por otra parte la función de memoria histórica y patrimonial del cristianismo y la folklorización del hecho religioso que le da todavía un lugar, una esperanza, subsiste en las personas, al menos en términos de religión civil, sin que se traduzca en ellos en una participación efectiva en la vida eclesial y una toma de conciencia de la misión evangélica. Hay como una tensión entre una oferta religiosas aún esperada por muchos y una voluntad de «ir al corazón de la fe» tomando en serio la libertad del acto de fe y, por eso su singularidad en una sociedad en la que el Dios de los cristianos no es ya una evidencia cultural. Hay una tensión entre una lógica de ventanilla y una lógica de proyecto.

Es precisamente en este contexto en el que los diáconos corren el riesgo de que se les perciba como un «ministerio de suplencia presbiteral», por citar la misma expresión de la Comisión teológica internacional. Ésta diagnostica la situación tipo del desarrollo del diaconado en algunas Iglesias locales, sobre todo en Europa occidental y en América del Norte, que conocen a la vez una disminución considerable del número de sacerdotes y de comunidades «habituadas a una importante gama de servi$\operatorname{cios}^{25}$ ». Llamados, o más sencillamente llevados a actuar en parroquias en el ámbito litúrgico y sacramental (asambleas dominicales no eucarísticas, homilías, bautismos, matrimonios, unción de enfermos, etc.), los diáconos llevan a cabo tareas en otro tiempo desempeñadas por sacerdotes y, del hecho mismo de su ordenación y de su presencia en el altar, son comúnmente percibidos como sucedáneo de los sacerdotes, de «sub-sacerdotes» de productos de sustitución ${ }^{26}$. Aún más, una encuesta entre los diáconos de habla francesa de Bélgica al principio de los años 90 mostraba que, si se les diese ocasión, la mayoría de los diáconos (54\%) estarían dispuestos a ser ordenados presbíteros mientras que una minoría (3\%) prefería que-

25 CTI, «Le Diaconat», p.90.

${ }^{26}$ Es uno de los puntos de partida de mi reflexión en A. BORRAS «Puntos para una teología del diaconado», Prêtres diocésains 1371 (99) 622-644) ¿No se habría restablecido más que un simple producto de sustitución que está sobre todo difundido en los países de vieja cristiandad marcados por una penuria o disminución de sacerdotes? Esta hipótesis severa merecería ser verificada en el plano de la sociología religiosa y teología pastoral. 
dar como diácono, la ausencia de respuesta de otros (43\%) es al menos revelador de una perplejidad, pero no punto de oposición ${ }^{27}$.

De cara al difícil paso de una lógica de ventanilla para satisfacer las necesidades religiosas de nuestros conciudadanos y pese a las veleidades de una presencia eclesial coherente y consecuente institucionalmente con la salida de la sociedad de cristiandad, es preciso constatar las lentas evoluciones sobre el terreno, los aplazamientos de muchos de los pastores, el temor de soltar la presa de unos, las ilusiones nostálgicas de otros. En Occidente, se llega bastante tarde para una respuesta teológica a la necesidad de presbíteros. La tendencia ¿no sería, como por inercia, volver a los diáconos para diferir las elecciones valientes que se imponen? Por otro lado, con el aumento del número de diáconos tras el retiro profesional, hay razones para creer que se lleve a estos diáconos, si no se les llame a trabajar en el ámbito parroquial cumpliendo principalmente tareas litúrgicas y sacramentales.

En estas circunstancias, es, ciertamente, más difícil hacer emerger la singularidad del ministerio diaconal. Resultado: hay dificultades para definir bien el diaconado en vías de restauración, enseguida se mezcla la imagen típica de las comunidades católicas bajo el efecto de «la atenuación eucarística» y en fin se corre el riesgo de mantener, pese a los encantos sobre los tiempos nuevos para el Evangelio, una pastoral de encuadramiento religioso, de división parroquial en zonas, de religión civil.

La «reactivación» del diaconado se ha operado en un marco de monopolio ministerial de los sacerdotes, de salida laboriosa de la sociedad de cristiandad, de persistencia ilusoria de lo que no será más por desplazamientos o sustituciones de mala ley. $\mathrm{Su}$ restablecimiento sólo puede hacerse efectivo si afrontamos la tarea de la elaboración de una teología del diaconado a la vez que una teología práctica, serenamente crítica y lúcidamente consecuente, capaz de pensar teológicamente y de orientar con audacia los cambios pastorales que sugiere una toma más en serio de la modernidad, de sus horizontes y sus límites. ¿No es también en esta condición $y$, en definitiva, en este último fondo, como una teología del diaconado tendrá toda su pertinencia para pensar este ministerio y sobre todo para ponerlo en práctica?

27 P. MASKENS, «Una encuesta sobre los diáconos francófonos de Bélgica», en A.HAQUIN y PH WEBER (ed.), Diaconat siglo XXI. Actas del coloquio de Louvain-la Nueve (13-15 septiembre 1994), Lumen Vitae-Novalis-Cerf-labor et FIDES, 1997, p.228 